\title{
Marketing Plans for Faculty Development: Student and Faculty Development Center Collaboration for Mutual Benefit
}

\author{
Victoria Mundy Bhavsar, Steven J. Skinner \\ University of Kentucky
}

Our faculty development center engaged senior-level business students as consultants to help us inform instructors about our resources. The students argued that organizational and marketing tasks are critical to our pedagogical work as they create opportunities for the pedagogical work to occur. This chapter describes the collaboration, the students' recommendations, and the center's response. Engaging students, our ultimate clients, in setting priorities for our center was a powerful learning experience for both us and them. Other centers may wish to use our experiences as impetus to collaborate with students on their campuses.

$\mathrm{T}$

eaching and faculty development centers are sometimes asked to argue their value to their institutions by demonstrating positive impacts in tangible terms, such as helping faculty to raise their student evaluations, make classes more accessible through the use of technology, and perhaps to find ways that they enjoy teaching more and so have higher morale. The catch is that a center can achieve these outcomes only if instructors participate in the center's activities and use its resources. A constant challenge for faculty development centers is to inform faculty and other instructors on their campuses about their services and resources, and a further problem is to convince instructors to use those services. Many centers find themselves struggling to create and maintain a strong presence on campus and to engage instructors. Brookfield (2007) observes, "For many of us, just getting teachers to show up 
at faculty development events is a triumph in itself" (p. 67). Issues of adding value, communicating to clients, and enticing clients are quite similar to the problems that businesses face when selling their products or services, and in fact faculty development centers have been likened to service firms within larger organizations (Nyquist, 1986).

Strategic marketing plans are often used as part of an organization's overall strategic plan. A marketing analysis provides detailed descriptions of the environment of the organization, the potential clientele or customers, an analysis of the organization itself, and specific goals and implementation plans for marketing the services or products of the organization. Almost any kind of organization can use a marketing plan, and many do, including universities (Cohen, 2006). Certainly teaching and faculty development centers can use strategic marketing plans, but a survey of two decades of To Improve the Academy, as well as a search of the Professional and Organizational Development Network's email listserv archives, indicated that centers may not use marketing plans much or at least do not communicate formally about their use of marketing plans. Practices and concepts from the business world are relevant for faculty development centers, but unless a member of a center's staff has a business background, no one in the center may have the expertise to apply business organization tools to the center's needs. Outside consultants can be sought, but they are usually costly.

The University of Kentucky's (UK) teaching center was a fairly new organization on campus and had been grappling with the well-known challenges just described. The center solved the problem of needing expert marketing advice by engaging senior-level business students as expert consultants. These students created full-length strategic marketing plans for the center as a capstone class project. This collaboration provided business expertise for the center, a client-based project for the students to apply their skills, and involved students deeply in teaching improvement initiatives on campus. Although students are the ultimate beneficiaries of a teaching center's services, they are not often included as partners in campus initiatives to improve teaching, and are even more rarely involved in setting priorities for the center (Cox \& Sorenson, 2000). This chapter describes the collaboration between the teaching center and the students, the students' recommendations for the center's activities, and the center's response. We end with reflections on the relationship between the students and the center. 


\section{Institutional Background}

$\mathrm{UK}$ is a land-grant research university with very high research activity and several professional schools. It has more than 25,000 students, nearly 2,000 full-time faculty members, approximately 450 part-time instructors, and about 1,900 graduate teaching assistants (GTAs). The Teaching and Academic Support Center (TASC) at UK was created in 2003 by combining several units that provided different kinds of assistance to teachers, including a traditional faculty development center. TASC's mission is to provide services to enhance undergraduate education at the university. Currently, the center has five resource or service groups: audio-visual, instructional technology, distance learning, graphics and multimedia, and educational (faculty) development. The total number of staff is about 50, with 3 devoted to educational development. TASC is located in one of the health science buildings at the southwestern edge of campus and has a small satellite facility in a large classroom building near the center of campus, where many undergraduate classes are held.

Educational development experienced a loss of visibility and usage on campus when the previous faculty development center, the Teaching and Learning Center (TLC), was incorporated into TASC. The TLC had high name recognition on campus. Faculty now talk about the loss of the TLC and its pedagogical resources without realizing that TASC has people who are equipped to help them. TASC itself has been perceived by some faculty and administrators as mostly a technology and audio-visual center. These misperceptions are marketing problems.

\section{The Project}

In summer 2005, a TASC staff member in the educational development group contacted the UK Gatton School of Business and Economics to locate a marketing class that would be willing to help address TASC's marketing problems. Dr. Steve Skinner, who taught the senior capstone marketing class, responded. The previous year, 2004-2005, Dr. Skinner had changed the design of the course from content delivery based on lectures, problems, and case studies, to a client-based, experiential class in which teams of students created marketing plans for local businesses or organizations. He had not yet identified local partners for his fall 2005 class and was willing to partner with TASC.

The class was divided into five teams of five students each. Early in the semester, a TASC staff member visited the class to introduce the center, describe its function in the university, and explain why the center wanted help. For the 
first part of the semester, the course proceeded traditionally, with students learning content through lectures, readings, and so on. In the last week of October, students began to apply their learning to TASC, engaging in a series of five progressive assignments that culminated in the production of their marketing plans. The teams presented their work on a weekly basis to each other and to a business faculty panel arranged by Dr. Skinner. The panel provided detailed, expert critique to the teams, who were directed to improve their work based on the feedback. The teams competed with one another every week for points. Dr. Skinner described the procedure as a cross between the popular television shows The Apprentice and American Idol, both featuring stiff competition and severe feedback.

During the creation of the plans, the student teams visited TASC, taking the initiative to make contact and set up meetings. They queried the heads of each service group about its clientele and work, perceived barriers to faculty's use of the service, and the service group's plans for the future. The director of TASC informed the students about the center's budget and categories of spending. The teams also examined TASC's web site. Three teams even created an email or phone survey that they administered to a small sample of UK faculty, department chairs, and deans. At the end of the semester, the center received all five marketing plans, and the group with the most points and the best marketing plan identified by Dr. Skinner won the competition. This winning plan was impressive in its thoughtfulness and professional presentation. Team members received a cash prize provided by TASC ( $\$ 1,000$ to split among themselves) and appropriately high grades. Other teams did not receive a prize but received appropriate grades. Every student in the class ended up with an authentic marketing product in hand to display to prospective employers.

The pedagogical benefits of client-based projects are well described in the marketing education literature (for a good summary, see Lopez \& Lee, 2005) and include active learning, skill development in a realistic setting, and heightened motivation. The collaboration between Dr. Skinner's class and TASC represented a medium- to large-scale client-based project, one that could be completed in a few weeks but required students to do significant background work and produce a full-scale marketing analysis and plan (Lopez \& Lee, 2005).

\section{The Marketing Plans and TASC's Response}

The students' reports were typical strategic marketing plans, each including an executive summary, an introduction, a situational analysis, a target market analysis, a SWOT (strengths, weaknesses, opportunities, threats) analysis, and 
marketing objectives, strategies, tactics, implementations, and controls. As the delineation of sections in marketing plans is not hard and fast, some repetitiveness among sections resulted.

\section{Situational Analysis}

The situational or environmental analysis contained the students' detailed descriptions of TASC and its place in the university. Students described objective factors such as the center's organizational structure and history, location, budget, staff complement, physical assets, and the like. This analysis also included legal issues such as confidentiality and adherence to the university's code of conduct, financial issues such as funding streams, and "social" or campus cultural issues such as the perception of TASC and the value placed on teaching improvement around campus. The students identified the center's competitors, the most important being the faculty's competing activities. TASC's limited use of media and technology to advertise itself was also a feature of the environment. In other words, the "situation" was the mise-enscène in which the center operated.

The students analyzed how these environmental factors affected TASC's activities. One team described the center as having an identity problem owing to its location in the health sciences buildings instead of a central campus location appropriate to undergraduate education. The team described TASC's services as unmemorable because most services represented "just-in-time" problem solving, easily forgotten when the problem was solved, and reported that TASC was hampered by its pattern of waiting for faculty to approach rather than seeking opportunities to develop programs proactively. This team concluded that many of the center's resources were underutilized if instructors were not having (or not dealing with) problems, a result of the reactive ways of working that TASC had developed. While this analysis identified some negative environmental factors not under the center's control, it clearly showed that the center had created other negatives for itself.

\section{-Target Market Analysis}

The target market analysis described faculty demographics such as age distribution, tenure status, and gender. Three of the five teams proposed ways to segment the target market of "all faculty" so that programs and services could be created for and directed to the people most likely to use them. One team proposed segmentation based on their perception of two major faculty orientations toward teaching improvement: "pioneers" or "set in their ways." Another team divided faculty into "high users" and "low users" of the center's services. 
These students found that health science faculty were by far the highest users of TASC's technology and multimedia services, probably because these services had previously been available for health sciences and TASC was physically located in the health science area. Two teams, including the first team mentioned earlier, identified a group of unserved potential clients, GTAs, who were not included in TASC's responsibilities even though GTAs contributed to undergraduate education.

This section of the marketing plans was the least surprising to members of TASC, who were generally aware of the characteristics of teachers on campus. The most important outcome of the target market analyses was having undergraduate students so emphatically identify GTAs as contributing to undergraduate education. This opened the door, administratively, for the center to reach out to GTAs.

\section{Strengths, Weaknesses, Opportunities, and Threats}

All student teams identified similar strengths, weaknesses, opportunities, and threats for TASC. TASC's strengths included the wide variety of available teaching services-for example, someone with questions about engaging students could talk to an educational development specialist about active learning and to an instructional technologist about designing online activities. The fact that all of the center's services were free was another strength. In addition, TASC had no direct competition on campus, being the only teaching center. The students also perceived TASC as a resource for the university as it moved toward its goals of rising in the national institutional rankings, and they considered TASC's potential contributions to university goals as a strength.

To the students, TASC's most obvious weaknesses included its noncentral, low-visibility main facility, low name recognition on campus, lack of advertising and marketing, and an unsuccessful web site with an ineffective visual image. Two other weaknesses were more subtle. First, because the center was an amalgamation of several units, its staff did not have a history of working in teams across service unit lines. A lack of synergy, and therefore a lack of effectiveness, was the result. Second, the exclusion of GTAs was the result of an emphasis on dealing with faculty only. To complicate matters, GTA services were housed in the graduate school. The consequence was that TASC did not, and to some extent could not, engage this large segment of people who contributed to undergraduate education.

The students also identified several opportunities that TASC could capitalize on to become more effective around campus. In the marketing plans, "weaknesses" were reclassified as "opportunities" if they could be relatively easily addressed. The web site and the center's visual image were the most ob- 
vious of these weaknesses-turned-opportunities. A critical opportunity was the fact that, because TASC was a relatively new unit on campus, it still had time to develop an identity and to market its services. The students described TASC's specialized staff and their ability to learn and adopt new technology as points in its favor. An opportunity to extend the center's reach was the opening of a satellite office on the central campus. Finally, TASC's most vital opportunity was that most faculty on campus wanted to be good teachers and would use available resources for that goal, provided that the resources were the right ones at the right time.

Threats included outside factors that might negatively affect TASC's ability to gain recognition as the campus's central authority and resource for teaching improvement. Interestingly, the students described two issues as threats that, to TASC staff, were not threats at all. First, the students thought that if faculty talked to one another about teaching problems, rather than consult TASC, the center's position as the source of teaching expertise was threatened. Second, the students identified learning tools packaged in textbooks as threats for a similar reason. To the contrary, the center's personnel considered these other resources to be opportunities because they provided openings by which faculty might become interested in getting more and different resources that TASC could then provide.

The students all identified, unerringly, the worst threat to TASC and especially educational development: the lack of time for faculty and other teachers on campus to engage with the center's services. If instructors did not have time to use TASC's resources, the resources themselves would become useless. One team identified an emotional threat, namely faculty's real feelings about having problems with teaching. Educational development personnel had thought that faculty might not want to engage in development activities for fear of their colleagues' reactions ("If you need to go to the teaching center, you must be inferior"). The students found that faculty were actually more concerned about their own feelings of inadequacy ("If I need to go to the teaching center, I must be inferior"). This was a subtle but important distinction in thinking.

\section{Marketing Objectives, Strategies, Implementations, and Controls}

All student teams created similar objectives for TASC, although their target numbers differed somewhat. The students intended to increase awareness of TASC among all faculty, GTAs, and other instructors to $90 \%-100 \%$, and 
they said that clients' satisfaction with the center's services should be high. All students intended to increase client usage by about $10 \%-20 \%$ per year. Finally, all teams suggested that TASC needed to be perceived positively by its target market. Certainly, these objectives were interrelated. The strength of the marketing plan was the clarity with which the students communicated criteria for success-the objectives were quantifiable and could be monitored. Students suggested strategies for accomplishing the objectives and monitoring progress at a level of detail that included naming the TASC members who should be responsible for implementing each tactic.

Every student team suggested changing the center's visual image on its web site and campus communications. The original visual image was a light, vertically fading teal depiction of the acronym TASC, with no representation of teaching. The students felt that the weak color did not convey strength and innovation, and the lack of a teaching symbol made the image ambiguous; the logo was not identifiable as that of a teaching resource center. Three teams presented new logos that they felt communicated the center's nature more clearly. Although TASC did not use these logos, its graphic and multimedia group did create a new image for the center's web site and communications. This image had bright colors and pictures of teachers and students.

Every student team also suggested refining the center's web site. The original one was composed of existing, unedited content from the web sites of the units that made up TASC. The site was hard to navigate, had no search engine, and few images. Most of the content was in large text blocks unsuitable for on-screen reading. In short, the original web site was unimpressive and unproductive, especially problematic for a center whose services included web site and instructional technology design and deployment. Finally, the site link was buried within the university web page rather than appearing prominently in resource lists for faculty and staff. In the web site redesign, all existing content was updated, corrected, and reorganized, and the educational development group created substantial new content for pedagogy and teaching resources. TASC plans to get a link placed on the university home page.

All of the students recommended increasing general advertising and promotion of TASC through such predictable methods as emails, flyers, posters, brochures, open houses, and promotional items. They suggested creating better signage for TASC's main facility, which was not easy to find in the health science building complex, and for the satellite facility on the central campus. Most importantly, the students emphasized that promotion needed to be "someone's job," rather than "everyone's job" (and therefore no one's job), and 
three teams suggested hiring a new staff member, or at least an intern or student worker, dedicated to marketing. At the time of this writing, signage has been enhanced for the satellite facility but not the main facility. Promotion and advertising are still haphazard although two recurring communications have debuted: an annual insert in the campus-wide faculty and staff newsletter and a weekly or biweekly educational development announcement email sent to a growing listserv.

Two of the five student teams suggested changing the center's name. TASC is pronounced "task," which is "a matter of considerable labor or difficulty" (Random House, 2006), and the students found this off-putting. Of course, the acronym stands for the "Teaching and Academic Support Center," but the students did not care for the word "support," either, as it implied to them that the center's clientele need crutches or counseling. These are not attractive messages to people whose identities depend on intellectual competence. One team proposed changing the center's name to the "Academic Center for Excellence," or $\mathrm{ACE}$, as a strong, positive representation of the center's goals and position on campus. The other team suggested simply changing the word "support" to "service." Changing the center's name was more complicated than the students realized, and we did not act on this recommendation.

Most of the students realized the significance of enlisting faculty and administrators to promote the center. Although gathering administrative support and faculty buy-in are well recognized as critical steps in promoting faculty development (Aitken \& Sorcinelli, 1994; Lang \& DeCaro, 1989), students are typically unaware of the status of teaching on campus and the role of administrators in promoting teaching. We felt that the students' insight into the necessity of administrative support was quite impressive. One team proposed a "college ambassador" program in which one or two well-respected faculty members in each college would be paid a small stipend to forward messages and announce TASC events in their colleges. Another team suggested engaging our university's president, himself an enthusiastic former teacher, in a recurring informal event that would bring people together to talk about teaching. The third team recommended working closely with deans' offices to ensure the relevancy of the center's programs and the deans' help in promotion. TASC has begun to engage faculty members as advisors, but not as formal ambassadors, and it has begun cultivating relationships with deans and other upper administrators.

The students were unable to suggest effective solutions to one of TASC's most pressing concerns: how to create a single, cohesive, highly functional organization from five historically separate units. One team at least recognized the problem and proffered a limited solution: a four-step user process in 
which clients would create an online profile and check in online, meet with an initial consultant, identify and use appropriate services, and complete an evaluation. The purpose of this process was to gather and track data to ensure that clients' needs were completely identified and met, and any problems could be solved quickly and seamlessly. TASC had already implemented the two essential middle steps of this process. The center had also previously tried to create a relational database, which would have accomplished almost exactly what the students suggested. This initiative failed because some people had difficulty with the software and because some service groups were reluctant to participate. TASC is still working to become a fully mature, united, and completely effective organization.

\section{The Students' Response}

All of the students who participated in this project have now graduated. We were able to speak to two of the five students involved in the winning team. From the students' perspective, the collaboration provided a client-based situation in which they could learn and practice the skills involved in creating a marketing plan for a real organization. Both students reported that the client-based project was an excellent learning experience, a true capstone in the sense of integrating years of undergraduate learning. The competitive aspect of the project motivated this team and reflected the "real business world"; the prize was a nice bonus but was not the main motivation for their effort. Having the marketing plan to display was a positive factor in their employment searches.

These two students also reported that their team worked well together. They were able to decide which tasks could be effectively divided and assigned to individuals and which tasks needed to be handled face to face. Unlike some of the less successful teams, this team had five highly motivated members and none who dragged. Both students were pleased to have learned to work in teams to prepare themselves for careers that require constant collaboration. Interestingly, both students have been surprised at how much teamwork their jobs require.

Both students expressed appreciation for Dr. Skinner's work in arranging the experience for them. One student reported being disappointed by "knowing from the beginning that [their] ideas probably would not be used." This, of course, was a misperception, as TASC has adopted several of the students' important recommendations, but the student's words underline the need for client partners to follow up with students after projects are completed. 


\section{TASC's Response}

As already described, the center tangibly responded to this collaborative project by implementing a number of the recommendations in the students' plans. This section explores what TASC staff members, in particular those staff in educational development who spearheaded the project, learned from seeing their organization, and even their profession, from an entirely new and unexpected viewpoint. Cox and Sorenson (2000) describe several ways that students have been invited to share their unique vantage point in teaching development-for example, as short- or long-term consultants or classroom observers, as members of faculty learning communities, and as participants and co-presenters in teaching seminars. All such activities empower students to improve teaching and learning. In this project, we empowered students by inviting them, as experts in their field, to advise us how to run our center and do our work better. What we did is no different from what we want faculty to do by seeking our expert services to improve their teaching.

If the experts have done their job well, a strategic marketing plan is a highly detailed, analytical document, sometimes painfully honest, that seriously addresses an organization's imperfections. As the students were relatively unhampered by considerations of university political issues and the history of our center, we saw our center through the eyes of young businesspeople whose sole concern was to solve our problems and help us sell our services, aggressively if necessary. Their basic themes were refreshingly straightforward: identify clientele and their needs, communicate widely both internally and around campus, and monitor client satisfaction. These tasks are neither difficult nor surprising, but they require constant work that is not directly related to pedagogy, advising, and the scholarship of teaching. The students pointed out that organizational and marketing tasks are as important to our pedagogical work as the pedagogical work itself as they create opportunities for the pedagogical work to occur. For us, this was a significant realization, requiring a shift from insisting on our own priorities to valuing the priorities of our clients. Previously it had been easy to give lip service to client needs while continuing with business as usual, but we could not change our clientele's priorities without changing our own first.

We were surprised at the power these ideas took on because they came from students. For us, the students had a dual identity as outside experts and our ultimate clients. In their roles of outside experts, they did impressively professional work. Because of their roles as our ultimate clients, we could not ignore the students' thoughtful analysis and unequivocal directions. Of 
course, we cannot say what our response would have been to nonstudent, professional, paid consultants, but our sense is that students' ideas were more meaningful to us, more likely to be taken seriously, especially because their work was so good.

We did not consider our center "weak" because of issues with reaching and engaging our clientele. To reiterate an earlier point, soliciting high participation is a constant challenge for faculty development centers at many universities and colleges. The challenge is more difficult for a newly formed center such as TASC, and we look forward to greater success as we implement our marketing plans. Involving students, our ultimate clients, benefited us, and the students themselves benefited by completing a meaningful project for a real organization on their campus. We hope that our experience with the students will stimulate other faculty development centers to consider partnering with business students on their campuses.

\section{References}

Aitken, N. D., \& Sorcinelli, M. D. (1994). Academic leaders and faculty developers: Creating an institutional culture that values teaching. In E. C. Wadsworth (Ed.), To improve the academy: Vol. 13. Resources for faculty, instructional, and organizational development (pp. 63-77). Stillwater, OK: New Forums Press.

Brookfield, S. D. (2007). A critical theory perspective on faculty development. In D. R. Robertson \& L. B. Nilson (Eds.), To improve the academy: Vol. 25. Resources for faculty, instructional, and organizational development (pp. 55-69). Bolton, MA: Anker.

Cohen, W. A. (2006). The marketing plan (5th ed.). Hoboken, NJ: John Wiley \& Sons.

Cox, M. D., \& Sorenson, L. D. (2000). Student collaboration in faculty development: Connecting directly to the learning revolution. In M. Kaplan \& D. Lieberman (Eds.), To improve the academy: Vol. 18. Resources for faculty, instructional, and organizational development (pp. 97-127). Bolton, MÄ:Anker.

Lang, H. G., \& DeCaro, J. J. (1989). Support from the administration: A case study in the implementation of a grassroots faculty development program. In S. Kahn (Ed.), To improve the academy: Vol. 8. Resources for student, faculty, and institutional development (pp. 71-79). Stillwater, OK: New Forums Press.

Lopez, T. B., \& Lee, R. G. (2005). Five principles for workable client-based projects: Lessons from the trenches. Journal of Marketing Education, 27(2), 172-188. 
Nyquist, J. D. (1986). CIDR: A small service firm within a research university. In M. Svinicki, J. Kurfiss, \& J. Stone (Eds.), To improve the academy: Vol. 5. Resources for student, faculty, and institutional development (pp. 66-83). Stillwater, OK: New Forums Press.

Random House. (2006). Random House unabridged dictionary. Retrieved May 17, 2007, from http://dictionary.reference.com/browse/task 